Nuit blanche

\title{
Deux ou trois choses que je sais d'elles
}

\section{Francine Bordeleau}

Numéro 20, octobre-novembre 1985

URI : https://id.erudit.org/iderudit/20344ac

Aller au sommaire du numéro

Éditeur(s)

Nuit blanche, le magazine du livre

ISSN

0823-2490 (imprimé)

1923-3191 (numérique)

Découvrir la revue

Citer cet article

Bordeleau, F. (1985). Deux ou trois choses que je sais d'elles. Nuit blanche, (20), 20-20.

Ce document est protégé par la loi sur le droit d'auteur. L'utilisation des services d'Érudit (y compris la reproduction) est assujettie à sa politique d'utilisation que vous pouvez consulter en ligne.

https://apropos.erudit.org/fr/usagers/politique-dutilisation/ 


\section{LITTÉRATURE ÉTRANGĖRE}

par Francine Bordeleau

\section{DEUXOUTROSGIOSES}
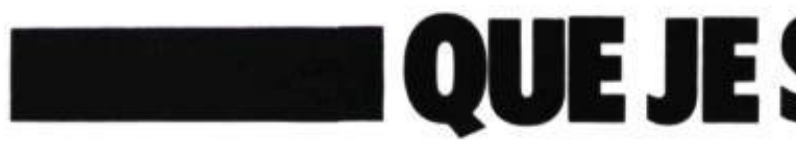

SAIS

D

FLES

L 'aristocratie est sans aucun doute la plus fascinante des classes sociales. Non seulement en ce qu'elle brille si ostensiblement, mais en ce qu'elle offre une homogénéité aussi parfaite, qu'elle se produise à New York ou en Australie. Nivellement ni par le haut ou par le bas, comme il est coutume de le dire, mais par la diamanterie.

Et voilà que dans toute cette redondance s'avance une échappée alors que s'inscrivent les aléas de la géographie et des us locaux: nous tombons, dans la lecture, sous l'emprise des variations indigènes. Et une énigme s'impose d'évidence: on ne s'engueule tellement pas de la même façon chez l'esthète que chez le prolétaire, qu'on se demande d'où tout ça parle. Le «passe-moi le beurre» y formant un réseau complexe, voire incompréhensible, de codes mystérieusement chiffrés, il est heureux que l'auteur - un parvenu - nous traduise cette sémiologie étrangère.

Ravis sommes-nous, donc. Jusqu'à ce qu'un homme et une femme, toujours les mêmes, viennent nous gâcher la subtilité. L'histoire, avec son «h» ornementé, trace des invariables réseaux sentimentaux: à la fin, qui du mâle conquérant ou de sa diaphane femelle craquera le premier, n'en pouvant mais devant l'opacité des préjugés sociaux? Lui, évidemment, puisqu'elle, celle par qui le scandale arrive, est déjà rompue à l'ostracisme.

Jusqu'ici, rien de neuf. De ce lui et de cette elle, tous les clichés y sont, avec les variantes locales pour la diversion: l'aristocratie est en effet plus sauvage et plus musclée en Aus-

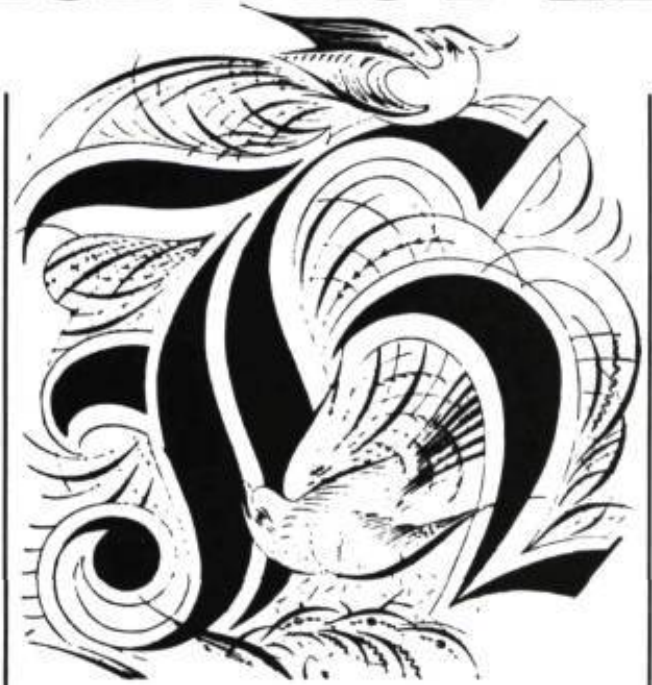

tralie qu'à Boston. On peut toutefois croire sur parole les romanciers qui, depuis des temps immémoriaux, se font les scribes fidèles de leur époque ou d'une autre qu'ils ont choisie par littérature interposée. De retrouver chez des individus aussi dissemblables que l'Australien Patrick White, les Américains Edith Wharton, Henry James et Francis Scott Fitzgerald de même que le Viennois Arthur Schnitzler une aussi belle unanimite sur le contenant - le rond de jambe tenant souvent lieu d'âme, on prendra garde de sous-estimer l'importance de la ciselure - parle de soi.

Il y a certes les privilèges que confère la géographie. Tellement que l'on pourrait presque prétendre que la littérature est d'abord affaire de climat. Que peut, par exemple, une Américaine bien née contre un Viennois fin de siècle? Le dernier draine avec lui des siècles d'idées, de fastes et de décadences multiples. Un couple, ça n'est toujours qu'un homme et une femme, ce qui dès lors limite les possibilités; les conversations, quand en plus on a les idées, prennent l'aspect d'une vision du monde.
Nul ne sachant ce qui est prétexte et ce qui est substance, on ne peut qu'admirer cette simultanéité qui nous est donnée à lire. C'est ainsi que se définit le roman mondain: quand rien ne s'extrapole de l'expérience. Les "fidèles peintures de l'époque» ne seraient alors que fatuité, qu'un exercice trop facile pour mériter un autre nom.

Et quand cette légèreté a tout écrasé, laissant sur son passage des parfums musqués et des objets encombrants, Fitzgerald nous propose l'aristocratie comme une affaire de look. Et quand ce look se ternit, il reste des tragédies magnifiques, à peine évoquées comme telles. Comme quoi le grandiose, le vrai, peut naître si intensément de la nuance. Et de ce lui et de cette elle, tout se déplace vers un ailleurs étrange, la conversation devenant un dépaysement de l'intime. Le sens, loin de l'évidence, est, indubitablement. Se révèle alors, sans se donner, cette âme que l'on désespérait d'entendre. Tout cela tend, dans le vivre, à la grandeur. Et c'est peut-être parce qu'elle ne se supporte pas qu'immanquablement, on en déchoit.

\section{Bibliographie}

Patrick White. Une ceinture de feuilles, Gallimard, coll. "L'imaginaire», 1985, 9,50 \$.

Édith Wharton. Le temps de l'innocence, Flammarion, 1985.

Arthur Schnitzler. Vienne au crépuscule, Stock, 1985, 17,95 S.

Henry James. Les Bostoniennes, Denoël, $1985,22,00 \$$.

Scott Fitzgerald. Tendre est la nuit, Belfond, $1985,17,50$ S. 